\title{
"I Apology no no I Mean I Am Sorry ... Please Let Me Explain That First": Enhancing Communicative Language Competence of Thai University Students Through CEFR-Based Online Intercultural Communication
}

\author{
Rutthaphak Huttayavilaiphan ${ }^{1}$ \\ ${ }^{1}$ Department of English, School of Liberal Arts, University of Phayao, Phayao, Thailand \\ Correspondence: Rutthaphak Huttayavilaiphan, Department of English, School of Liberal Arts, University of \\ Phayao, Phayao, Thailand.
}

Received: October 10, 2021

Accepted: November 12, 2021

Online Published: November 19, 2021

doi:10.5539/jel.v11n1p87

URL: https://doi.org/10.5539/jel.v11n1p87

\begin{abstract}
During this COVID-19 pandemic, no one can deny the value of online communication. It has saved our lives by preventing us from going outdoors and becoming infected, while also facilitating achievement of various personal and professional goals. Online communication can also assist us with our academic goals, whether it is used to communicate with supervisors or with people from other lingua-cultural backgrounds to practice the language. This form of communication is emphasized in the Common European Framework of Reference for Languages (CEFR) framework, which is one of the most significant guidelines for language teaching and learning throughout the world. The present research has two aims: first, to determine the extent to which CEFR-based online intercultural communication can improve Thai students' communicative language competence, and second, to investigate Thai students' attitudes toward CEFR-based online intercultural communication and international volunteers. The results received from 15 fifth-year dual B.A. (Chinese) and B.CM. (Traditional Chinese Medicine) students and international volunteers using various research instruments revealed that Thai students could increase their communicative language competence after participating in CEFR-based intercultural communication activities. This encompassed linguistic, sociolinguistic, and pragmatic abilities that correspond to the CEFR (2001) scales. In terms of attitudes, the study indicated that, because they were more confident in their communicative language ability, they had a positive attitude toward the CEFR-based online intercultural communication activities and their international volunteers. Finally, further research on this topic should include a proper design of online communication activities as well as methods for assessing students' competency both before and after participation.
\end{abstract}

Keywords: CEFR, online communication, communicative language competence, intercultural communication

\section{Introduction}

\subsection{Online Communication}

During the midst of the COVID-19 epidemic, it seems impossible to deny the importance of online communication. In particular, when the World Health Organization (2020) has advised people all across the world to maintain social distancing and stay at home to reduce infections, online communication has become a significant form of their social interactions and engagements in different domains (Kaçar, 2021; Nguyen et al., 2020; Wong, Ho, Olusanya, Antonini, \& Lyness, 2021). To support this point, Kaçar (2021) argued that the use of online communication through the internet and social media has become more popular among people because it could provide them with distance learning, remote jobs, and virtual socializing environments, which cannot be performed through face-to-face communication during the pandemic's lockdowns and social isolation.

Indeed, online communication is not a new phenomenon in our society. It has been utilized for a variety of purposes since the late twentieth century (Harasim, 2000; Wood \& Smith, 2004). According to O'Murchu, Breslin and Decker (2004), many individuals use online communication for both professional and personal purposes, such as increasing company advancements and managing dating and meeting offline. Vrocharidou and Efthymiou (2012), on the other hand, described that some people use online communication for academic 
purposes, such as when students use email and instant messaging to interact with supervisors regarding classroom teaching.

\subsection{Online Communication in English Language Teaching and Learning}

Regarding the field of English language teaching and learning, online communication has been perceived as an important method that can facilitate students' learning. According to Al-Sofi (2016), online communication is like a portal that allows students to attain the other parts of language learning. Hence, besides its major role in increasing input and output language skills, online communication has provided significant possibilities for the development of other components of language learning. Such aspects include building the learners' vocabulary, being more self-confident, boosting their motivation and positive attitudes toward others and their cultures, and decreasing language use anxiety. In addition, Pasfield-Neofitou (2012) stated that one of the most frequently mentioned benefits of online communication for language learners is that it offers access to native speaker peers. It may also help to increase literacy and can supplement formal study. Additionally, online communication can provide interesting and crucial opportunities for language acquisition by making contextual materials, authentic communication, correction, and peer feedback accessible. Moreover, Ke and Cahyani (2014) and Ke and Suzuki (2011) considered that using online communication in English language classes can improve students' intercultural communicative competence. This is because, through online communication, students not only learn the language, but also practice cultural negotiation with their partners, who typically come from various lingua-cultural backgrounds. This issue is regarded as critical in the current era when English is used as a lingua franca (henceforth ELF) in intercultural settings among non-native English speakers (NNESs) more often than with native English speakers (NESs). This is according to the traditional view of English communication, which focuses more on the NESs' and NNESs' communication (Baker, 2012; Sharifian, 2009).

\subsection{CEFR, Online Communication, and Plurilingualism}

The Common European Framework of Reference for Languages (CEFR) is a well-known framework in the field of English language teaching and learning. According to Little (2006), it was initially issued in 2001 by the Council of Europe as a guide for documenting the achievements of foreign language learners, as well as to provide a framework for the development of language syllabuses, curricular standards, tests, textbooks, and other language learning tools throughout Europe. However, according to Foley (2019), the original edition of CEFR (2001) faced several criticisms either about its application or its scientific basis. In terms of application, CEFR has been criticized for allowing policymakers to use linguistic skill levels as gatekeepers without having a comprehensive needs assessment. In terms of scientific criticism, CEFR was criticized for how it developed and validated the level descriptors, such as their wording and the lack of attention to multilingualism in its scales.

In 2018, another edition called 'the Companion Volume to the CEFR' was released (CEFR, 2018). In this edition, the Council of Europe (2018) introduced additional scales for language activities that were not covered by the CEFR (2001), such as online communication and plurilingualism. They considered online communication to be important in language learning and teaching, especially when twenty-first century students are regularly exposed to a screen during their daily activities, for example, when they chat on Facebook Messenger and post pictures on Twitter at the same time. As a result, online communication was regarded as an important aspect of a student's language competence, and an aspect that language teachers should be aware of, alongside listening, writing, reading, and speaking (Cinganotto, 2019; Foley, 2019). As for plurilingualism, according to the Council of Europe (2018), this refers to an uneven and changing competence, in which the user/learner's resources in one language or variety may be very different in nature to those in another. That is, language students need to have some communication strategies, such as the ability to switch from one language or dialect (or variety) or express oneself in one language (or dialect, or variety).

Given the CEFR's emphasis on online communication in the current period of plurilingualism and English as a global language, it can be interpreted that language students need to possess some types of communicative competence in order to become successful online communicators in plurilingual communication situations. Therefore, the researcher perceives that one aspect of CEFR (2001) known as 'communicative language competence' may be a method that could help Thai students to communicate with people of different backgrounds in the future. This frequently involves linguistic, sociolinguistic, and pragmatic abilities. The present research, thus, aimed to: (1) determine the extent to which CEFR-based online intercultural communication can increase Thai students' communicative language competence, and (2) investigate Thai students' attitudes toward CEFR-based online intercultural communication and international volunteers. The following are the research questions that guided the research process: 
1) To what extent can CEFR-based online intercultural communication activities increase the communicative language competence of Thai students?

2) What are the attitudes of Thai students toward the CEFR-based online intercultural communication activities and international volunteers?

\section{Method}

\subsection{Research Setting}

This qualitative research was conducted at a public university in northern Thailand. This university has approximately 20,000 students who come from different regions of the country (e.g., northern, central, eastern, and southern regions) as well as from northern mountainous areas. Also, since 2015, when Thailand joined the ASEAN Economic Community (AEC), this university has welcomed international teachers and students from other Asian nations to come to teach and study under the exchange program (e.g., from China and Cambodia). As a result, this university may be described as a context that includes people from many linguistic and cultural backgrounds. Furthermore, the university was chosen to represent another perspective on intercultural communication and the CEFR-based learning approach. Research of these aspects has never been conducted in this area but has been undertaken primarily in other areas of the country such as Bangkok and the surrounding areas (e.g., Charttrakul \& Damnet, 2021; Phaisannan, Charttrakul, \& Damnet, 2019; Waluyo, 2019).

\subsection{Research Participants}

\subsubsection{Thai University Students}

As presented in Table 1, the target participants of this research were 15 fifth-year university students (six males and nine females) who were pursuing dual-bachelor degrees (i.e., Bachelor of Traditional Chinese Medicine or B.CM. and Bachelor of Arts Program in Chinese language or B.A Chinese language) at the target university. They were chosen by the use of the convenience sampling procedure from a total of 42 students who were enrolling in an English course entitled 'Public Speaking and Presentation' (Subject Code 146232) in the summer semester of the academic year 2020. These participants were multilingual speakers because, apart from their mother tongue, which is the Thai language, they were able to use the English language (i.e., English proficiency levels ranged from A2 to B1 based on the placement test of the CEFR-based courseware called 'DynEd' or Dynamic Education) and the Chinese language (i.e., Chinese proficiency levels were between 4 and 5 according to the Hanyu Shuiping Kaoshi or HSK Chinese Proficiency Test).

Table 1. Background information of Thai university students

\begin{tabular}{llll}
\hline Student & Gender & DynEd level & HSK level \\
\hline TS1 & Male & B1 & 5 \\
TS2 & Male & A2 & 4 \\
TS3 & Male & A2 & 5 \\
TS4 & Male & A2 & 5 \\
TS5 & Male & B1 & 4 \\
TS6 & Male & A2 & 4 \\
TS7 & Female & B1 & 5 \\
TS8 & Female & A2 & 5 \\
TS9 & Female & A2 & 5 \\
TS10 & Female & A2 & 4 \\
TS11 & Female & B1 & 5 \\
TS12 & Female & B1 & 5 \\
TS13 & Female & A2 & 5 \\
TS14 & Female & A2 & 5 \\
TS15 & Female & A2 & 5 \\
\hline
\end{tabular}

\subsubsection{International Volunteers}

Another group of research participants included seven international volunteers (four males and three females). As seen in Table 2, they were from a variety of non-English speaking countries and held different educational levels and degrees. Since all of them had obtained their degrees from the UK university where the researcher also obtained his doctoral degree, the researcher was able to contact them via the university's alumni page on the Facebook website. He invited them to take part in a 12-week CEFR-based online intercultural communication 
with Thai students. Before signing their consent forms, the two main roles were explained to the volunteers, including to encourage intercultural communication with Thai students in order to enhance their communicative language competence based on the CEFR framework (see 2.3.1) and to observe to what extent Thai students can improve their communicative language competence both during and after each intercultural communication.

Table 2. Background information of international volunteers

\begin{tabular}{llllll}
\hline Volunteer & Gender & Age & Nationality & Level and major of study & Activity partner \\
\hline IV1 & Female & 30 & Greek & PhD Chemistry & TS1, TS2 \\
IV2 & Female & 28 & Bulgarian & MEng Software Engineering & TS3, TS4 \\
IV3 & Male & 28 & Chinese & MSc Marketing Management & TS5, TS6 \\
IV4 & Male & 22 & French & BEng Ship Science & TS7, TS8 \\
IV5 & Female & 32 & Mexican & PhD TESOL & TS9, TS10 \\
IV6 & Male & 27 & Malaysian & BSc Maths with Actuarial Science & TS11, TS12 \\
IV7 & Male & 33 & Indian & PhD Aerodynamics & TS13, TS14, TS15 \\
\hline
\end{tabular}

\subsection{Research Tools}

To gain data to answer the research questions, this study employed different research tools comprising the 12-week CEFR-based online intercultural communication activities, the Placement Test, online interviews, and conversational analysis.

\subsubsection{The 12-Week CEFR-Based Online Intercultural Communication Activities}

The 12-week CEFR-based online intercultural communication activities in this research were used to enhance Thai students' 'communicative language competence' based on the CEFR framework. The researcher focused on this aspect of the CEFR framework (2001) because it shares similar aspects (i.e., linguistic, sociolinguistic, and pragmatic or discourse competences) with Byram's (1997) Intercultural Communicative Competence (ICC), which is one of the highly influential models and has become an object of increased scrutiny over the course of the past decade in the field of intercultural communication (Hoff, 2020). Also, Byram's ICC model was often employed in previous studies that explored the impact of online communication on students' ICC (e.g., Avgousti, 2018; Kitade, 2012).

According to the Council of Europe (2001), linguistic competences encompass different aspects of language as a system, regardless of the sociolinguistic value of its variants or the pragmatic purposes of its realizations. It focuses on general range, vocabulary range, grammatical accuracy control, vocabulary control, phonological control, and orthographic control. Sociolinguistic competences are concerned with the socio-cultural contexts in which language is used. The sociolinguistic component has a strong influence on all language communication between representatives of different cultures, owing to its sensitivity to social conventions (e.g., etiquette rules, norms governing relations between generations, sexes, classes, and social groups, linguistic codification of certain fundamental rituals in the functioning of a community). Lastly, pragmatic competences are concerned with the functional use of linguistic resources (e.g., creation of language functions, speech actions), which are based on interactional exchange scenarios or scripts. It also covers discourse mastery, cohesiveness and coherence, text type and form identification, irony, and parody. This component emphasizes flexibility, turn-taking, thematic development, coherence, propositional precision, and spoken fluency (See Appendix A).

Focusing on the 12-week online intercultural communication activities, as previously mentioned in 2.2.2, the international volunteers were required to encourage the Thai students to communicate in English to enhance their CEFR communicative language competence. As shown in Table 3, apart from focusing on a different range of topics for communication (from personal to local and global topics), the volunteers also needed to insert different components of CEFR's communicative language competence either directly or indirectly in their online communication with the Thai students. For example, in Week 1, the volunteers and Thai students could begin using simple language to greet and introduce each other. Then, the volunteers could increase the complexity in their use of language (general range), such as talking about past events in life using past tenses. This activity may lead the Thai students to move beyond their comfort zone of using language (e.g., using only present tenses). It is worth noting that the activities utilized to improve the Thai students' CEFR communicative language competence were created and modified by the international volunteers themselves after they were briefly explained by the researcher. Furthermore, since the majority of intercultural communication among the Thai students and international volunteers took place via online written communication, some components of the CEFR communicative language competence, particularly those related to oral communication, were 
diminished (e.g., phonological control, orthographic controls, and spoken fluency).

Table 3. The 12-week CEFR-based online intercultural communication activities

\begin{tabular}{lll}
\hline Week & Focus for CEFR communicative language competence & Topic for communication \\
\hline 1 & Linguistic competence - General range & Greetings and self-introduction \\
2 & Sociolinguistic competence & Family and education \\
3 & Pragmatic competence - Flexibility and turn-taking & Hobbies and leisure time \\
4 & Linguistic competence - Vocabulary range & Movies and songs \\
5 & Sociolinguistic competence & Hometown festivals \\
6 & Pragmatic competence - Thematic development & City cuisines and attractions \\
7 & Linguistic competence - Grammatical accuracy & National cultures and traditions \\
8 & Sociolinguistic competence & National issues and problems \\
9 & Pragmatic competence - Coherence & Computer and technology \\
10 & Linguistic competence - Vocabulary control & Global warming and climates \\
11 & Sociolinguistic competence & Ways to improve English \\
12 & Pragmatic competence - Propositional precision & Thoughts about COVID-19 \\
\hline
\end{tabular}

\subsubsection{The DynEd Placement Test}

To investigate whether the Thai students' linguistic competence (which is an aspect of the CEFR communicative language competence) improved after they participated in the CEFR-based intercultural communication activities, the placement test of the courseware known as DynEd (Dynamic Education) was used. This courseware was purchased by the target university for improving the students' English proficiency, in particular for the general education courses. According to the DynEd Teacher's Guide (DynEd, 2016), the DynEd Placement Test provides a quick evaluation of language skills, with an emphasis on listening comprehension, grammar, and vocabulary. The placement test comes in two parts. The first part places students into the DynEd Certification Program courses A1 and A2 or indicates that a student should go on to take Part 2 of the test, while the second part places students into Certification Program courses A2 to C2. In addition, there are several types of questions in the test including multiple-choice items that test vocabulary and grammar, listening comprehension, sentence construction, and sentence order. On completion, the test will determine students' current level of fluency as described by the CEFR (22001) level descriptors as presented in Figure 1 below.

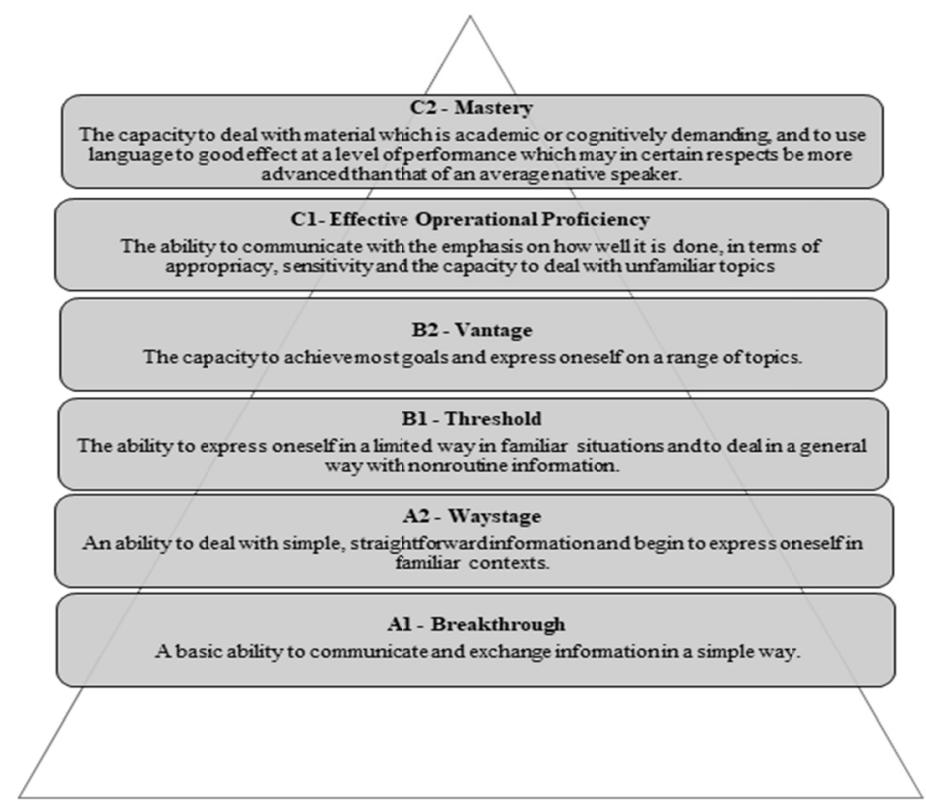

Figure 1. CEFR (2001) language level descriptors 


\subsubsection{Online Interviews}

An online interview is a common research method for gathering qualitative data from participants, such as their views and opinions. Online interviews, like offline interviews, usually ask respondents to describe what they think or feel about a certain element of their social lives (Lindlof \& Taylor, 2017). Furthermore, online interviews, according to Stromer-Galley (2003), can be beneficial for understanding the meanings that research participants attach to their activities, such as their viewpoints, motives, and experiences. For example, when the Thai students and international volunteers completed the last online communication activity, the researcher conducted an online interview session with them through the Facebook Messenger channel. The primary goal of conducting online interviews was to find out how much the Thai students' communicative language competency had increased after participating in online intercultural communication activities, as seen from the perspective of both the Thai students themselves and the international volunteers. The online interview with the Thai students was conducted in the Thai language, while the interview with the international volunteers was in English. After the interviews were completed, the researcher kept the interview data from Facebook Messenger on Microsoft Word documents for further analysis.

\subsubsection{Conversational Analysis}

In addition to other research tools, the researcher employed Conversational Analysis (CA) as a method for analyzing the online interaction between the Thai students and their international volunteers. Previous research explained that $\mathrm{CA}$ is a common approach for defining social interaction, shared meaning, mutual understanding, and human behavior coordination. Furthermore, it allows us to learn more about how people live their lives, build and maintain relationships, and define who they are to one another (Meredith, 2020; Stokoe, 2009). For example, in this research, after each week of the 12-week activity, the researcher requested that the Thai students sent reports of their chat with the international volunteers either in the form of word documents or computer screen captures. This enabled the researcher to examine how they used English (linguistic competence), demonstrated awareness of etiquette rules (sociolinguistic competence), and handled turn-taking (pragmatic competence). In addition, because a substantial amount of online communication nowadays relies on elements such as emojis, stickers, GIFTs, and photographs, the researcher incorporated these aspects into the conversation analysis of the Thai students and international volunteers' online interactions.

\section{Results}

\subsection{Answer to Research Question 1: To What Extent Can CEFR-Based Online Intercultural Communication Activities Increase the Communicative Language Competence of Thai Students?}

To address this research question, which concerns the improvement in the CEFR communicative language competence (i.e., linguistic, sociolinguistic, and pragmatic competences) of the Thai students after engaging in the CEFR-based online intercultural communication activities, different sources of data must be discussed. They include the DynEd Placement Test results, the interview results of the Thai students, the interview results of the international volunteers, and the results of CA of the online communication between the Thai students and international volunteers.

\subsubsection{The DynEd Placement Test Results}

As seen in Table 4, the results from the DynEd Placement Test showed that, after participating in the 12-week CEFR-based online intercultural communication activities, only four students (TS2, TS3, TS4, and TS9) received higher English language proficiency levels. That is, while the English proficiency levels of the other nine students remained unchanged, these four students moved from A2 (Waystage) to B1 (Threshold), or from being able "to deal with basic knowledge and to begin expressing themselves in a familiar context" to being able "to express themselves in restricted ways in familiar contexts and to cope with nonroutine information in a broad manner". Despite this shift in the CEFR-based placement test results, it may appear difficult to assert that the CEFR-based online intercultural communication activities have influenced the students' English language proficiency for a variety of reasons.

For one reason, compared to the students whose English language proficiency levels remained unchanged, the number of students whose English proficiency increased was quite small (i.e., only four out of fifteen students or 26.6 percent). Therefore, generalization of this small number with the rest of the student participants who also took part in the CEFR-based online intercultural communication activities would be unreliable. More importantly, according to the Guide to the CEFR for English Language Teachers published by Cambridge University Press (2003), students who obtain a higher level of CEFR will need more study and practice hours to move to the next level than students who receive a lower level. This might explain why none of the B1 students 
in this research were able to move to B2, whereas four of the A2 students were able to level up to B1. Most importantly, because the CEFR-based online intercultural communication activities were not directly generated from DynEd's courseware lessons, the students' DynEd's Placement Test improvement may not only be influenced by the CEFR-based online intercultural communication activities, but also by other extraneous factors, such as a close relationship between the Thai students and the international volunteers (see TS3 and IV2 in Excerpt 3) and a positive attitude toward error correction feedback (see TS4 in Excerpt 2). This issue of extraneous factors was often raised in previous studies that concerned the extraneous variables as a factor that can lead to misinterpretation in language assessment research (e.g., Damico, 1993; Haaf, Duncan, Skarakis-Doyle, Carew, \& Kapitan, 1999).

Table 4. Thai students' pre- and post-activity results of the DynEd placement test

\begin{tabular}{lll}
\hline \multirow{2}{*}{ Student } & \multicolumn{2}{c}{ DynEd Placement } \\
\cline { 2 - 3 } & Pre-Activity & Post-Activity \\
\hline TS1 & B1 & B1 \\
TS2 & A2 & $B 1^{*}$ \\
TS3 & A2 & $B 1^{*}$ \\
TS4 & A2 & $B 1^{*}$ \\
TS5 & B1 & B1 \\
TS6 & A2 & A2 \\
TS7 & B1 & B1 \\
TS8 & A2 & A2 \\
TS9 & A2 & $B 1^{*}$ \\
TS10 & A2 & A2 \\
TS11 & B1 & B1 \\
TS12 & B1 & B1 \\
TS13 & A2 & A2 \\
TS14 & A2 & A2 \\
TS15 & A2 & A2 \\
\hline
\end{tabular}

\subsubsection{The Interview Results of the Thai Students}

In contrast to the DynEd Placement Test results, which revealed only the linguistic competence improvement, the interview results could show both the linguistic and sociolinguistic competences of the Thai students. That is, based on the interview results, the Thai students expressed that their linguistic and sociolinguistic competences had improved as a result of participating in the CEFR-based online communication activities. In terms of linguistic competence, some of them stated that interacting in English with international volunteers had enhanced their vocabulary and grammatical skills. For example, in Excerpts 1 and 2, TS9 remarked that her volunteer taught her a lot of new vocabulary, while TS4 stated that his volunteer's feedback significantly educated him about grammar. With regard to sociolinguistic competency, TS5 stated that he increased his awareness of using language in society throughout the online communication activities, especially when he miscommunicated about COVID-19 in Excerpt 3.

\section{Excerpt 1: Interview 2 with TS9}

TS9:... my vocabulary knowledge seemed to have improved. I had to prepare a lot of vocabulary because the issues I had to discuss with my volunteer were so diverse. For example, if I were to describe my hometown, I would use a long list of words to describe things like traditions and tourist attractions. ... This is amusing since I picked up a lot of new words from my volunteer's explanation of his hometown in Mexico.

Excerpt 2: Interview 2 with TS4

TS4:I was first embarrassed because I made many grammatical errors, which my volunteer corrected with explanations. Later on, I understood that the more mistakes I made and the feedback I received, the more I learned. So, I believe that I will no longer make the same mistakes ...

Excerpt 3: Interview 2 with TS5

TS5:... you know, I made a huge mistake at the time. I typed something implying that COVID-19 was primarily caused by China. I had to apologize to my volunteer several times in both English and Chinese because I discovered my writing was too sensitive for him after he responded by saying "sorry for that" 
with a crying face emoji. I didn't mean to say that, I meant something different, but Google Translate had given me the wrong translation. This taught me to be more conscious of how I use language to interact with individuals of various backgrounds in society...

\subsubsection{The Interview Results of the International Volunteers}

In addition to the previous data sets, the interview results of the international volunteers could give more insights for the researcher as this data set showed improvements in all dimensions of students' CEFR communicative language competence, including linguistic, sociolinguistic, and pragmatic abilities. According to the results, the majority of the international volunteers stated that the Thai students had considerably improved their communicative language competence during the online communication activities. For instance, in Excerpt 4, international volunteer 3 (IV3) highlighted both linguistic and pragmatic improvements of his Thai-student partner (TS5). In addition, IV2 stated in Excerpt 5 that her Thai-student partner (TS4) had improved all aspects of CEFR communicative language competence. She assumed that TS4's improvement was due to their regular communication. That is, instead of chatting once a week and focusing only on the topic of communication based on the 12-week online communication activities, IV2 and TS3 wrote to each other every day to share about Korean dramas.

\section{Excerpt 4: Interview with IV3}

IV3: I think that TS6's language use and meaning expression have much improved. For example, at first, when he wished to discuss his past experiences, he primarily used the past simple tense. Later, I noticed that he tried to use more complicated tenses like present perfect and past perfect tenses. I don't know why he did it. He might be imitating me since I used multiple tenses to depict distinct patterns of activities in the past when I chatted with him.

Researcher: How about his meaning expression?

IV3: I believe that as we chatted more, he felt more comfortable sharing and connecting his views from my culture to his. For instance, when I explained to him about China's Lantern Festival, which promotes reconciliation, peace, and forgiveness among the Chinese people. He linked this event to the Loykratong Festival, in which Thai people also release the lanterns up to the sky to wish all their problems and bad luck away.

\section{Excerpt 5: Interview with IV2}

IV3: At first, TS3 used only simple vocabulary, grammar, and meaning expressions, so his communicative language competency was quite limited. But, after discovering that we both enjoy Korean dramas, instead of communicating once a week and focusing just on the topics you provided each week, we began chatting to each other every day. As a result, he improved in every aspect of his communicative linguistic competence.

Researcher: That's great. Can you tell me more about how he had improved all aspects of his communicative language competence?

IV3: For example, when he attempted to explain some issues in Korean dramas to me, he used a range of words that were wider than the first time we talked. He even used some Korean words with me. For sociolinguistic skill, if I can count his increase of concerns about gender differences in the later sections of our communication as an example, I think he had also improved this aspect. For example, after learning that I am an LGBTQ person, I observed that he was quite aware of how to use English words to explain gender differences, like when we were chatting about the Itaewon Class series which includes LGBTQ people. He may have thought that I would feel comfortable discussing it. ... Finally, his pragmatic competence, what I can think of is his improvement of turn-taking skills. In later sections of our chats about Korean dramas, I could see that he knew when to initiate and when to wait for me.

\subsubsection{The Conversational Analysis Results}

Similar to the results from the interview with the international volunteers, the CA results can present the improvement in all aspects of the CEFR communicative language competence of the Thai students. For instance, the CA results of online communication between TS5 and IV3 demonstrated that TS5 had improved not only his sociolinguistic competence (as presented in Excerpt 3), but also his linguistic and pragmatic competences. Regarding the linguistic competence, the results demonstrated that TS5 was not only able to notice his language errors (e.g., the use of "I apology" and "blaim"), but was also able to repair them (e.g., the use of "no no I mean I am sorry" and the replacement of the mistyped word "blaim" with "*blame"). TS5 was also able to use various 
types of sentences, including simple and compound sentences to communicate with his partner.

In terms of sociolinguistic competence, when TS5 discovered that his question "How about China? You are the origin of covid-19, right?" was not sociolinguistically competent and it had caused his Chinese volunteer's negative feeling (e.g., when IV3 said "yeah sorry for that" and used a crying-face emoji), TS5 then attempted to express his apology for this language use. This result shows that TS5 was concerned that his language use could be sensitive to other people who come from different cultural backgrounds.

Furthermore, the CA results revealed that in his English contact with IV3, TS5 employed a variety of pragmatic strategies. Such strategies included his skills in managing turn-taking and conversation initiation, particularly when he sought to explain his meaning behind the question "How about China? You are the origin of covid-19, right?" to his partner. That is, he used the phrase "no let me explain that first" to request his turn in the conversation so that his partner could understand the true meaning of his language usage before going on to the next issue of discussion. The CA findings also showed that TS5 utilized a pragmatic technique throughout his online conversation, such as when he used the Chinese language word “对不起” (which means I am sorry) to reinforce his apology. Finally, as shown in Figure 2, TS5 exploited some of the features provided in Facebook Messenger, such as the sad-face emoji, to express his guilt and to support the meaning of his language usage.

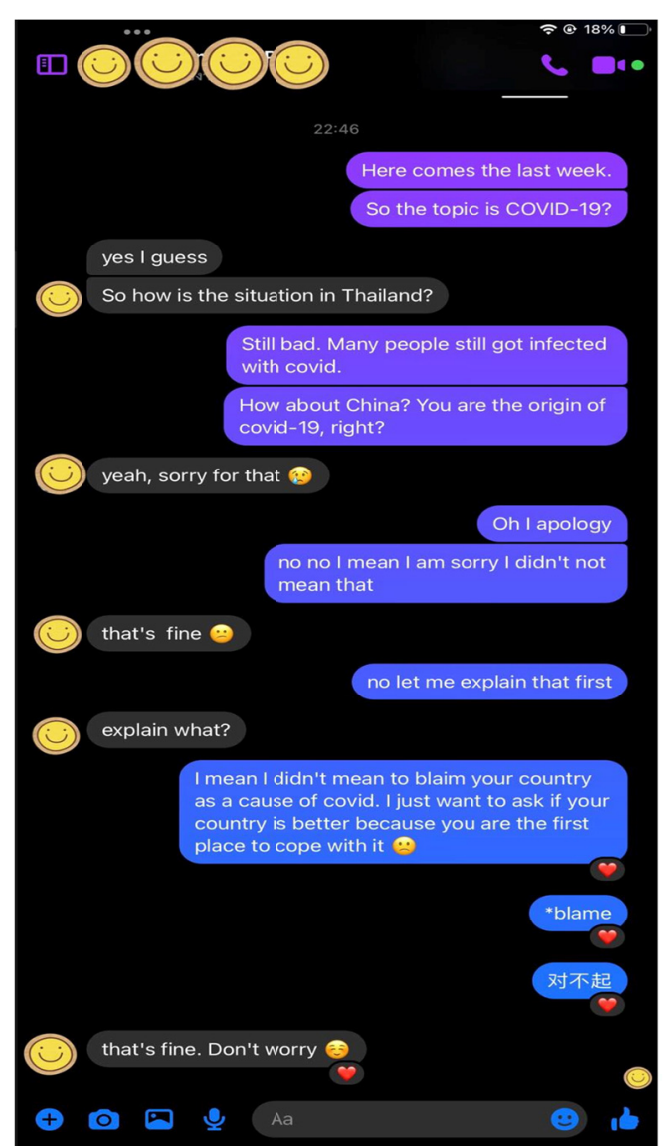

Figure 2. A conversation between TS5 and IV3

\subsection{Answer to Research Question 2: What Are the Attitudes of Thai Students Toward the CEFR-Based Intercultural Communication Activities?}

To answer Research Question 2, the researcher mostly relied on the findings of interviews conducted with the Thai students before and after their participation in the CEFR-based intercultural communication activities. According to the findings, despite their anxiety and nervousness before participating in the activities, the Thai students exhibited good attitudes toward both the online communication activities and the international volunteers. To illustrate, during her first interview session, TS11 claimed her lack of experience communicating in English outside of the classroom as a source of her concern about using the language, especially with people from other backgrounds. However, in the second interview, her confidence in using English had increased, not 
just because her international volunteer was supportive and helpful during the activities, but also because of her improvement in linguistic competence.

\section{Excerpt 6: Interview 1 with TS11}

TS11: ... I'm not sure if I'll be able to do it because I've never done anything like that before. I only use this language in classrooms with people I know well, such as my friends and instructors. I've never chatted in English with foreigners, particularly those from other countries. So, what should I do?

\section{Excerpt 7: Interview 2 with TS11}

TS11: ... She was so encouraging and kind. I mean she was always willing to help me when I couldn't explain things to her. I also feel that my English has improved as a result of this activity because I have learned more vocabulary and grammar rules. So, I think I'm confident to talk with her more ...

TS14 was another student who developed a positive attitude toward both the CEFR-based online intercultural communication activities and the international volunteers. Like TS11, TS14 expressed concern during the first interview session, noting her lack of opportunities to practice English with other people outside of the classroom as a hindrance to her English development and a source of her fear in participating in this online communication activity. Nonetheless, she reported in the second interview session that she felt more comfortable communicating in English since her volunteer had never criticized her language use. On the other hand, she was encouraged by her volunteer to use the language without worrying too much about errors or mistakes, because these elements might obstruct her fluency and naturalness throughout the English conversation.

Excerpt 8: Interview 1 with TS14

TS14: I think it will be difficult for me because I never use English with people I don't know. It could be easier if it's in Chinese, as I use it more often than English in daily everyday life...

Excerpt 9: Interview 2 with TS14

TS14: I think she is a very nice person to talk with because she never judged my language when I made mistakes. When I told her that I usually overthink about grammar and errors before typing, she said that these aspects will make my communication disrupting or even unnatural ... so thank you for inviting me to participate in this project and for motivating me to improve my English with her.

\section{Discussion}

\subsection{The Improvement in the Thai Students' CEFR-Based Communicative Language Competence Through CEFR-Based Online Intercultural Communication}

The results of several research instruments have proven that engaging in the CEFR-based online intercultural communication activities enabled the Thai students to increase their communicative language competence based on the CEFR framework, which comprises linguistic, sociolinguistic, and pragmatic competences. This is in accordance with previous research that claimed online communication to be essential to English students' communicative language competence (e.g., Ke \& Cahyani, 2014; Ke \& Suzuki, 2011; Mohamed, Ngadiran, Samad, \& Powzi, 2019) as well as those studies focused on the CEFR-based communicative language competence (Harjanne \& Tella, 2012; Nakatani, 2012). For example, apart from the DynEd Placement Test results that showed English language improvement of some Thai students (e.g., from level A2 to level B1), the interview results with the Thai students and international volunteers also found that online communication in English with people from various backgrounds had enhanced the Thai students' linguistic knowledge, such as when they used more complex sets of vocabulary (e.g., words related to local traditions and attractions in Excerpt 1) and grammar (e.g., using more complex tenses and sentences in Excerpts 4 and 5 as well as noticing and correcting language errors). This result is supported by Mohamed et al. (2019), who encouraged Malaysian and French students of English language to develop their language skills through online conversation. The findings revealed that their student participants not only improved their linguistic and communicative skills, but also were able to move beyond their comfort zone of using English language.

In terms of sociolinguistic competence, the results illustrated that the Thai students were aware of some social components that could affect their online communication with the international volunteers. Such components included cultures (e.g., cultural and contextual sensitivity in Excerpt 3) and genders (e.g., issues related to LGBTQ people in Excerpt 5). These sociolinguistic components, both cultures and genders, were seen to have a strong influence on intercultural communication amongst people from various backgrounds by previous empirical research and review papers (e.g., Hashemian \& Farhang-Ju, 2017; Marcoccia, 2012; Yingli \& Jin'ai, 2020). 
Regarding pragmatic competence, some Thai students performed better in terms of turn-taking initiations, such as when TS5 requested his turn in the conversation with IV3 in Figure 2 using the phrase "no, let me explain that first", and when IV3 described how TS6 frequently began the conversation after they discovered that they both enjoy Korean dramas. This result may contradict d'Eça (2003) who claimed that non-native English students may believe that turn-taking does not exist and that they can quickly lose their opportunity to participate in online communication with people who have greater language competence and better keyboarding skills. Aside from the issue of turn-taking, the results demonstrated that the Thai students had improved their ability to express meanings in English. This included when TS9 prepared specific words to tell her volunteer about the traditions and attractions in her hometown (Excerpt 1), when TS6 linked China's Lantern Festival with Thailand's Loykratong Festival (Excerpt 4), when TS3 used some Korean words to reinforce the meaning in his communication with IV3 who had also learned some Korean language from Korean dramas (Excerpt 5), and when TS5 used Chinese language and Facebook's features like emojis to support his meaning (Figure 2). Based on the assumptions of previous studies related to pragmatics and intercultural communication (e.g., Cogo \& House, 2017; Fang, 2010; Waugh, 2013), these examples of pragmatic strategies not only demonstrated that Thai students were effective online communicators, but also revealed their ability to become successful intercultural communicators in their future English communication which may be with people from different backgrounds.

\subsection{Thai Students' Attitudes Toward the CEFR-Based Online Communication and the International Volunteers}

According to the results, the majority of the Thai students had a positive attitude toward both the CEFR-based online communication and the international volunteers. In terms of the former, the Thai students explained their views in a similar way to student participants in previous studies, such as Ke and Cahyani (2014) and Ke and Suzuki (2011), and Mohamed et al. (2019), who perceived online communication with people from different backgrounds as a tool that helped them reduce their anxiety about using English and be more confident in communicating in English with foreigners.

With regard to the international volunteers, the Thai students viewed them positively because they were not only models of using vocabulary and grammar (Excerpts 2, 4, 5), but they also encouraged the Thai students to communicate in English without worrying too much about grammar or errors (Excerpt 7). This connects with studies by Ke and Cahyani (2014) and Ke and Suzuki (2011) who also found that when their participants, who were non-native speakers of English (NNESs), performed online communication in English with other NNESs from different countries, such participants could learn the language from observing others' usage of English. More importantly, their participants also felt less stressed because their NNES partners did not place much emphasis on grammar but on fluency to express their thinking.

\section{Limitations and Implications for Further Research}

It is crucial to highlight that the above results were confined to the target individuals and the target context of the present research. This implies that transferring the results of this research to other groups of research participants in different contexts may be difficult. More importantly, the research methodologies were developed to meet only the research objectives of the present study. Therefore, adapting them to other research contexts may provide different results. In particular, with regard to the 12-week CEFR-based online communication activities, the researcher should note that this research method was adapted from the CEFR (2001), which was the old version of the CEFR framework. Further research interested in applying the CEFR framework to enhance students' online communication may consider the Companion Volume published in 2018, which is more up-to-date with online communication. Most importantly, future researchers may consider using other placement tests to evaluate the quantitative results of students' improvement in English language based on the CEFR scale, as the DynEd Placement Test used was quite inconsistent with the CEFR-based online intercultural communication activities in this research. As a consequence, comparing and explaining the outcomes of students' English language competency levels before and after the CEFR-based online communication activities was deemed insufficient. This was the primary reason for including other qualitative research methods in this study to describe how the Thai students increased their communicative language skills to support the DynEd result.

Lastly, to gain another perspective on English learning and online communication, further research may encourage the participants to use other features that are also available for online communication, such as sending voice audios and video calling, which can enhance their spoken communication with communication partners. Then, the researchers may study whether or not the participants have a problem with the spoken language of the volunteers such as accents and pronunciation. This issue seems important for the present period when people from different lingua-culture backgrounds come into contact, not only in an online mode, but also in the face-to-face mode by the use of English as a lingua franca for their contact language. 


\section{Conclusion}

The aim of this research was twofold: (1) to study the impacts of the CEFR-based online intercultural communication activities on the improvement of Thai university students' communicative language competence and (2) to explore the attitudes toward the CEFR-based online intercultural communication activities and the international volunteers. The results from different research tools showed that the Thai students had significantly improved their CEFR communicative language competence including linguistic, sociolinguistic, and pragmatic competences. Therefore, they showed a positive attitude toward both the online intercultural communication activities and their international volunteers. These results are consistent with many former studies that perceived the impact of online intercultural communication on the language and communication skills of students of English language.

Further research that is also interested in this topic may need to ensure that the online communication activities used to enhance the students' communicative language competence are relevant to the descriptors of the CEFR framework. Also, the placement test used to evaluate the students' English language proficiency both before and after the online communication activities must follow the CEFR scales, otherwise it may be unreliable to describe the students' language improvement. However, researchers may use other research tools to support the results from the placement test, such as interviews and conversational analysis, as undertaken in this research. More importantly, to provide another perspective on the impact of online communication on students' English learning, further research may include a focus on spoken communication which is also increasingly popular in online communication.

\section{Acknowledgments}

The research was supported by University of Phayao (Unit of Excellence).

\section{References}

Al-Sofi, B. B. M. (2016). The impact of online communication on learning English: A case study of Saudi EFL learners. International Journal of Applied Linguistics English Literature, 5(4), 91-101. https://doi.org/10.7575/aiac.ijalel.v.5n.4p.91

Avgousti, M. I. (2018). Intercultural communicative competence and online exchanges: A systematic review. Computer Assisted Language Learning, 31(8), 819-853. https://doi.org/10.1080/09588221.2018.1455713

Baker, W. (2012). From cultural awareness to intercultural awareness: Culture in ELT. ELT Journal, 66(1), 62-70. https://doi.org/10.1093/elt/ccr017

Byram, M. (1997). Teaching and assessing intercultural communicative competence. Clevedon: Multilingual Matters.

Cambridge University Press. (2003). Introductory Guide to the Common European Framework of Reference (CEFR) for English Language Teachers. Cambridge University Press.

Charttrakul, K., \& Damnet, A. (2021). Role of the CEFR and English Teaching in Thailand: A Case Study of Rajabhat Universities. Advances in Language Literary Studies, 12(2), 82-89. https://doi.org/10.7575/aiac.alls.v.12n.2.p.82

Cinganotto, L. (2019). Online interaction in teaching and learning a foreign language: An Italian pilot project on the companion volume to the CEFR. Journal of e-Learning Knowledge Society, 15(1), 135-151.

Cogo, A., \& House, J. (2017). Intercultural pragmatics. In The Routledge handbook of pragmatics (pp. 168-183). Routledge. https://doi.org/10.4324/9781315668925-15

Council of Europe. (2001). Common European framework of reference for languages: Learning, teaching, assessment. Cambridge, U.K.: Press Syndicate of the University of Cambridge.

Council of Europe. (2018). Common European Framework of Reference for Languages: Learning, Teaching, Assessment. Companion Volume with New Descriptors. Strasbourg: Council of Europe Publishing.

d'Eça, T. A. (2003). The use of chat in EFL/ESL. TESL-EJ, 7(1).

Damico, J. S. (1993). Language assessment in adolescents: Addressing critical issues. Language, Speech, Hearing Services in Schools, 24(1), 29-35. https://doi.org/10.1044/0161-1461.2401.29

DynEd. (2016). DynEd Teacher's Guide: Placement Test for Cerfification.

Fang, J. (2010). A Study on Pragmatic Failure in Cross-Cultural Communication. Online Submission, 7(12), 42-46. 
Foley, J. (2019). Issues on the initial impact of CEFR in Thailand and the region. Indonesian Journal of Applied Linguistics, 9(2), 359-370. https://doi.org/10.17509/ijal.v9i2.20233

Haaf, R., Duncan, B., Skarakis-Doyle, E., Carew, M., \& Kapitan, P. (1999). Computer-based language assessment software: The effects of presentation and response format. Language, Speech, Hearing Services in Schools, 30(1), 68-74. https://doi.org/10.1044/0161-1461.3001.68

Harasim, L. (2000). Shift happens: Online education as a new paradigm in learning. The Internet Higher Education, 3(1-2), 41-61. https://doi.org/10.1016/S1096-7516(00)00032-4

Harjanne, P., \& Tella, S. (2012). Intercultural communicative competence, and its assessment: The CEFcult Helsinki higher education scenario. In Koulu ja oppiaineiden monet kulttuurit (pp. 41-54).

Hashemian, M., \& Farhang-Ju, M. (2017). Differences in EFL Learners' Requests to Faculty in Synchronous Computer-Mediated Communication: Case of Gender and Proficiency. Research in English Language Pedagogy, 5(2), 181-202.

Hoff, H. E. (2020). The Evolution of Intercultural Communicative Competence: Conceptualisations, Critiques and Consequences for 21st Century Classroom Practice. Intercultural Communication Education, 3(2), 55-74. https://doi.org/10.29140/ice.v3n2.264

Kaçar, G. Y. (2021). Online Communication During Pandemic. Paper presented at the 3rd International Congress on Multidisciplinary Social Sciences, Turkey.

Ke, I. C., \& Cahyani, H. (2014). Learning to become users of English as a Lingua Franca (ELF): How ELF online communication affects Taiwanese learners' beliefs of English. System, 46, 28-38. https://doi.org/10.1016/j.system.2014.07.008

Ke, I. C., \& Suzuki, T. (2011). Teaching global English with NNS-NNS online communication. Journal of Asia TEFL, 8(2).

Kitade, K. (2012). An exchange structure analysis of the development of online intercultural activity. Computer Assisted Language Learning, 25(1), 65-86. https://doi.org/10.1080/09588221.2011.584512

Lindlof, T. R., \& Taylor, B. C. (2017). Qualitative communication research methods. Sage publications.

Little, D. (2006). The Common European Framework of Reference for Languages: Content, purpose, origin, reception and impact. Language Teaching, 39(3), 167-190. https://doi.org/10.1017/S0261444806003557

Marcoccia, M. (2012). The internet, intercultural communication and cultural variation. Language Intercultural Communication, 12(4), 353-368. https://doi.org/10.1080/14708477.2012.722101

Meredith, J. (2020). Conversation analysis, cyberpsychology and online interaction. Social Personality Psychology Compass, 14(5), 285-294. https://doi.org/10.1111/spc3.12529

Mohamed, M. N. A., Ngadiran, N. M., Samad, N. A., \& Powzi, N. F. A. (2019). E-Collaboration among Students of Two Regions: Impacts on English Language Learning through Peer Learning. International Journal of Learning, Teaching Educational Research, 18(9). https://doi.org/10.26803/ijlter.18.9.11

Nakatani, Y. (2012). Exploring the implementation of the CEFR in Asian contexts: Focus on communication strategies. Procedia-Social Behavioral Sciences, 46, 771-775. https://doi.org/10.1016/j.sbspro.2012.05.196

Nguyen, M. H., Gruber, J., Fuchs, J., Marler, W., Hunsaker, A., \& Hargittai, E. (2020). Changes in Digital Communication During the COVID-19 Global Pandemic: Implications for Digital Inequality and Future Research. Social Media + Society, July-September (3), 1-6. https://doi.org/10.1177/2056305120948255

O’Murchu, I., Breslin, J. G., \& Decker, S. (2004). Online Social and Business Networking Communities. Paper presented at the ECAI Workshop on Application of Semantic Web Technologies to Web Communities.

Pasfield-Neofitou, S. E. (2012). Online Communication in a Second Language: Social Interaction, Language Use, and Learning Japanese. Multilingual Matters. https://doi.org/10.21832/9781847698261

Phaisannan, T., Charttrakul, K., \& Damnet, A. (2019). The CEFR-TBL in Fostering Thai Pre-service Teachers' English-Speaking Ability Using the Peer Interview Task. Advances in Language Literary Studies, 10(5), 10-19. https://doi.org/10.7575/aiac.alls.v.10n.5p.10

Sharifian, F. (2009). English as an international language: Perspectives and pedagogical issues (Vol. 11). Multilingual Matters. https://doi.org/10.21832/9781847691231

Stokoe, E. (2009). Doing actions with identity categories: Complaints and denials in neighbor disputes. Text and 
Talk, 20(1), 75-97. https://doi.org/10.1515/TEXT.2009.004

Stromer-Galley, J. (2003). Depth interviews for the study of motives and perceptions of Internet use. Paper presented at the International Communication Association Conference, San Diego, CA.

Vrocharidou, A., \& Efthymiou, I. (2012). Computer mediated communication for social and academic purposes: Profiles of use and university students' gratifications. Computers Education, 58(1), 609-616. https://doi.org/10.1016/j.compedu.2011.09.015

Waluyo, B. (2019). Examining Thai first-year university students' English proficiency on CEFR Levels. The New English Teacher, 13(2), 51-51.

Waugh, E. (2013). Teaching pragmatics and intercultural communication online. TESL Canada Journal, 98-98. https://doi.org/10.18806/tesl.v30i7.1154

Wong, A., Ho, S., Olusanya, O., Antonini, M. V., \& Lyness, D. (2021). The use of social media and online communications in times of pandemic COVID-19. Journal of the Intensive Care Society, 22(3), 255-260. https://doi.org/10.1177/1751143720966280

Wood, A. F., \& Smith, M. J. (2004). Online communication: Linking technology, identity, \& culture. Routledge.

World Health Organization. (2020). Coronavirus disease (COVID19) advice for the public. Retrieved from https://www.who.int/emergencies/diseases/novel-coronavirus-2019/advice-for-public

Yingli, Z., \& Jin'ai, S. (2020). Using Social Media to Promote Intercultural Communication Between Chinese and American University Students. Chinese Journal of Applied Linguistics, 43(2), 169-187. https://doi.org/10.1515/CJAL-2020-0011

\section{Appendix A}

\section{Components of Communicative Language Competence in CEFR (2001)}

\begin{tabular}{|c|c|c|}
\hline Component & Focus & Description \\
\hline \multirow{6}{*}{$\begin{array}{l}\text { Linguistic } \\
\text { competence }\end{array}$} & General range & The ability to use more complex language and move beyond comfort zone \\
\hline & Vocabulary range & The ability to use broad and various words and expressions \\
\hline & $\begin{array}{l}\text { Grammatical accuracy } \\
\text { control }\end{array}$ & $\begin{array}{l}\text { The ability to accurately recall 'prefabricated' expressions and the ability to focus on } \\
\text { grammatical structures while expressing thought }\end{array}$ \\
\hline & Vocabulary control & The ability to choose an appropriate expression from their repertoires \\
\hline & Phonological control & The ability to perform sound articulation, prosodic features, accentedness and intelligibility \\
\hline & Orthographic control & The ability to copy, spell and use layout and punctuation \\
\hline $\begin{array}{l}\text { Sociolinguistic } \\
\text { competence }\end{array}$ & Sociolinguistic & The knowledge and skills required to deal with the social dimension of language use \\
\hline \multirow[t]{6}{*}{$\begin{array}{l}\text { Pragmatic } \\
\text { competence }\end{array}$} & Flexibility & $\begin{array}{l}\text { The ability to adapt language learnt to new situations and to formulate thoughts in different } \\
\text { ways }\end{array}$ \\
\hline & Turn-taking & The ability to take the discourse initiative \\
\hline & Thematic development & $\begin{array}{l}\text { The way in which ideas are logically presented in a text and related to each other in a clear } \\
\text { rhetorical structure }\end{array}$ \\
\hline & Coherence & $\begin{array}{l}\text { The use of language strategies like as reference, substitution, ellipsis, and other kinds of textual } \\
\text { cohesion, as well as logical and temporal connectors and other types of discourse markers, to } \\
\text { weave the various components of a text into a cohesive whole }\end{array}$ \\
\hline & Propositional precision & The ability to pinpoint how to formulate what one wishes to express \\
\hline & Spoken fluency & $\begin{array}{l}\text { The ability to construct utterances, despite hesitations and pauses (lower levels), to maintain a } \\
\text { lengthy production or conversation, and to ease and spontaneity of expression }\end{array}$ \\
\hline
\end{tabular}

\section{Copyrights}

Copyright for this article is retained by the author, with first publication rights granted to the journal.

This is an open-access article distributed under the terms and conditions of the Creative Commons Attribution license (http://creativecommons.org/licenses/by/4.0/). 